\title{
Determination of the Significance of Environmental Impacts of Development Projects: A Case Study of Environmental Impact Assessment of Indrawati-3 Hydropower Project in Nepal
}

\author{
Ram B. Khadka ${ }^{1}$, Ajay Mathema ${ }^{1}$, Uttam Sagar Shrestha ${ }^{2}$ \\ ${ }^{1}$ School of Environmental Science and Management, Pokhara University, Nepal; ${ }^{2}$ Departments of Geography, Tribhuvan University, \\ Kathmandu, Nepal. \\ Email: khadka7777@hotmail.com,ram.khadka@aemsregional.org
}

Received May 28 ${ }^{\text {th }}, 2011$; revised July $7^{\text {th }}, 2011$; accepted August $26^{\text {th }}, 2011$.

\begin{abstract}
The environmental impacts are commonly quantified in the EIA studies by rating, ranking and scaling. The National EIA Guidelines, 1993, Nepal provides a guideline to score the impacts in terms of magnitude, extent, and duration. This step is commonly known as impact prediction in the EIA process. The predicted scores are multiplied by the weightage value of the resource likely to be affected. The application of the weightage transforms the predicted values of the impacts into their "significance"-a concept used in the environmental decision making. In other words the significance value entails assignment of relative judgment values to the impacts. The impacts, thus, can be ranked based on their significance. The impact ranking is more useful in evaluating the socio-economic impacts. Unlike air, water and noise quality, which can be assessed against established standards; the socio-economic impacts do not have standard scale and are difficult to rank. Importance weighting of socio-economic impacts are commonly determined by the consensus obtained from the interaction with the local people, agencies, NGOs and experts. The impact ranking in the EIA process is unavoidable, firstly to prioritize the urgent environmental issues and design mitigation measures accordingly and also provide coherent linkages among the issues, and plan monitoring and auditing linkage with the proposed mitigation measures. Furthermore, it also provides strong basis for decision making, and thus facilitates the decision makers. The process of impact prediction, determination of significance and ranking were applied in the EIA of Indrwati-3 Hydroelectric Project, which is one of the successful cases of EIA in Nepal. The authors believe that the impacts predicted and quantified through this method are focused on the local concerns since it seeks an active involvement of the local people who are likely to be affected.
\end{abstract}

Keywords: Environmental Impact Assessment, Environmental Significance, Ranking, Prediction of Impacts, Importance Weighting, Judgment Values

\section{Introduction}

Environmental Significance is an anthropogenic concept [1] used in decision making of the Environmental Assessment process. This concept remains undefined and has become a source of controversy among the EA professionals. Evaluation of the environmental significance requires expert judgment values and scientific criteria [2]. However, EIA legislation of developed and developing countries has catagorically mentioned that the law is enforcable only if the impact is environmentally significant. The legal definition of environmentally significant in terms of thresholds is usually not available [1]. Duinker and Beanlands [3], Huge et al. [4], Sadler (1996), Gilpin [5] and Thompson [2] have proposed various definition of environmental significance and the common elements of their definitions are following [1].

- Environmental significance is a judgment,

- The degree of environmental significance depends upon the nature of the impacts (type, magnitude, extent and duration),

- The importance is based on biophysical and socioeconomic values, and the amount of changes to the environment perceived to be acceptable to the com- 
munity.

Determination of the significance entails the assignment of relative judgment values of impact prediction associated with the project and to determine the priority order in which the impacts are to be avoided, mitigated or compensated [6]. Evaluation of the significance of the predicted impacts can be made in different ways depending on particular environmental component in question. For example air, water and noise quality can be assessed against the established quality standards whereas changes in socioeconomic conditions are more difficult to evaluate [1].

The major elements of assessing the significant impacts have been described for ecological and socio-economic components and the assessment is mostly based on subjective evaluation and includes the following [3]:

1) Ecological Component: This includes the criteria related to ecology and environmental parameters critical to the operation of valued ecosystem such as

- Plant and animal habitats,

- Rare, endangered and threatened species of biodiversity,

- Ecosystem resilience, biodiversity and carrying capacity, and

- The viability of local species.

2) Social and Economical Components: Effects on biophysical impacts when translated into human concerns; the following effects are to be considered:

- Effect on human health and safety,

- Loss of commercially productive lands,

- Loss of public resources such as social services,

- Loss of transportation and other infrastructures, and

- Demography.

3) Environmental Standards: The use of national standards enshrined into legislation/rules of the government/agencies are the most common means to assess the environmental significance. In most nations, standards/ criteria for air/water/noise are available for reference [6].

While evaluating the impact significance, the current status of the environment is analyzed. This is followed by identification and prediction of potential impacts of the proposed action. In the third stage, it is determined whether the receiving environment will be able to absorb the effects of the predicted impacts without suffering irreversible change. This requires thorough understanding of their resilience of receiving environment. It is also required to evaluate whether the proposed proposal is within the scope of national policy and covered by the existing legislation and regulation and lastly the degree of public interest [7].

\section{Procedures for Determination of Significance}

Rau and Wooten [8] and Canter [9] have provided some practical tools in evaluating environmental significance of development projects. According to them, the effects should be predicted in terms of magnitude, extent and duration.

For the prediction, a number of ways have been proposed such as symbolic signs, numerical values, $(+)$ for positive and (-) for negative effects, etc. However, the most convenient way is to develop impact ranking framework as proposed by Canadian Federal Environmental Assessment Review [10]. National Environmental Impact Assessment Guidelines. Nepal has also adopted similar impact ranking method and applied successfully in number of cases [11]. The impacts are predicted and classified in terms of:

Magnitude: It is determined based on severity of impact. In case of high magnitude, the situation turns to be irreversible. Medium and low magnitude is thus considered to be reversible and acceptable by the public.

The spatial extent: This is another characteristic of the impact and indicates the zone of influence. The effects of the impacts may be of local or national or regional or international scopes.

Duration of impact: This is the temporal aspects of impacts, indicating how long the effects can last. Based on the prediction made on the above characteristics of the impacts, the following numerical values are assigned to each of the character and the degree on which they are likely to occur [11] (Table 1).

Each impact is predicted with its magnitude, extent and duration and respective scores. The total scores of all three parameters are often computed.

Importance weighting schemes are the most structured approach to impact scaling and permit direct transformation of impact ranking into impact significance. In order to determine the appropriate weightings of the resource expected to be affected, a procedure should be followed. While assigning values for resources the EIA study group, professionals, stakeholders, academicians, and knowledgeable people from the project area should be involved in the series of meetings and discussions. An interaction table is usually prepared where resources anticipated to be affected should be listed on the vertical column and the importance weighting should be marked in the horizontal column with the degree of importance from 1 to 3 where 1 indicates the least importance and 3 indicates the highest importance. Request should be made to the participants to fill out the table based on their own perceptions. The numerical values of the column are then summed up and individual value in the column is divided by the total value. This gives relative weighting of each resource to be considered [8].

The total score of magnitude, extent and duration is 
Table 1. Categorization of impacts and their ranking.

\begin{tabular}{ccc}
\hline Magnitude & Extent & Duration \\
\hline High/major (H) 60 & Regional $® 60$ & Long-term (Lt) 20 \\
Moderate (M) 20 & Local (L) 20 & Medium-term (Mt) 10 \\
Minor (L) 10 & Site Specific (SP) 10 & Short-term (St) 05 \\
\hline
\end{tabular}

Source: National EIA Guidelines, 1993.

multiplied by corresponding relative weightings of resource which is the significance of that particular impact. In this way, significance can be determined for all the impacts identified and further consideration for impacts and mitigation measures can be proposed [6].

\section{A Case Study on Determination of Environmental Impact Significance of Indrawati-3 Hydropower Project in Nepal}

Nepal is endowed with enormous hydropower potential. However, only a small fraction of it has been exploited so far. Additional quantity of power is required to fulfill the power need of the country. Implementation of Indrawati-3 hydropower was one of the responses to fulfill the power need. The project started in 2002 and completed in 2007 and generated electricity which contributes to National grid.

Indrawati-3 hydropower project was constructed in Sindhupalchowk district located $58 \mathrm{~km}$ north-east of Kathmandu-the capital city of Nepal. The head work was built in the bank of Lapse River and the power house was located in Ratmate village. The project covers three village development committees viz Lagarche, Jaymire and Bhotenamlang (See map Figure 1).

\subsection{Project Area Description}

The project is located within the mid-hills of mountain at the altitude of $2000 \mathrm{~m}$ to $2500 \mathrm{~m}$ above the sea level. The geology of the project area consisted mainly quartzite, phyllities and schist. The sedimentation in river is quite high and the specific load was recorded at $0.304 \times 10^{6}$ $\mathrm{m}^{3} /$ year.

Indrawati is a snow-fed river originating from the Jugal Himal range. The maximum flow of Indrawati River near project area is $40.5 \mathrm{~m}^{3} / \mathrm{sec}$ in average and minimum flow is $6.5 \mathrm{~m}^{3} / \mathrm{sec}$ recorded during the months of February to March. In the project area, a few patches of vegetation comprising particularly Lyonia ovalifolia, Pinus ruxburghii, Alnus nepalensis, Castanopsis indica, and Shorea robusta were present. Some species of the mammals and birds were reportedly available in the area but no rare, endangered and protected species were available. Among the fish species in Indrawati River, 20 species of the fresh water fish existed in the River with a few migratory species. The project area covered only three Village Development Committees, consisting 7500 populations and were mostly farmers, traders, and service holders.

\subsection{Project Description}

The project consisted of 5-meter high diversion weir constructed at the intake site, $2.9 \mathrm{~km}$ long headrace tunnel, a surface type of power house with 3 generating sets, $2.8 \mathrm{~km}$ long access road and accommodation complex for workers and staff. The project was designed to divert water flow of $17.2 \mathrm{~m}^{3} / \mathrm{sec}$ from the River to the tunnel and the power house to generate electricity. As per the rules $0.5 \mathrm{~m}^{3} / \mathrm{sec}$ of water flow has been released as environmental flow for downstream during the dry period. The project required occupying 120 ha of land. Most of the land was acquired from the local farmers with adequate compensation. Approximately, 1500 workers were employed during the project construction and in the operational stage, only 45 project staffs were employed [12].

\subsection{Environmental Impact Assessment (EIA)}

As per the requirement Environmental Protection Regulation of Government of Nepal [13], hydropower project generating more than $5 \mathrm{MW}$ required to undergo an EIA process to obtain environmental clearance from the government of Nepal prior to the start of project construction. Accordingly, an EIA was carried out for this project; for which scoping and TOR documents were prepared and were approved by the government on July 282004 [14] The EIA study including public hearing was completed on August 2005 and was submitted to the concerned agency of the government for approval. The EIA was approved by the government on October 2005. The project was constructed and operated by a local Hydropower company called "National Hydropower Company" [15] and the electricity generated through this project is purchased by Nepal Electricity Authority (NEA).

\subsection{Methodology}

After the approval of Scoping and TOR documents from the concerned agency of the Government of Nepal, EIA study was carried out. During the study, information on the baseline conditions of the project area were collected and compiled. Impact identification was made following the methods given in National Environmental Impact Guidelines, 1993 and particularly the following methods were adopted [16]: 


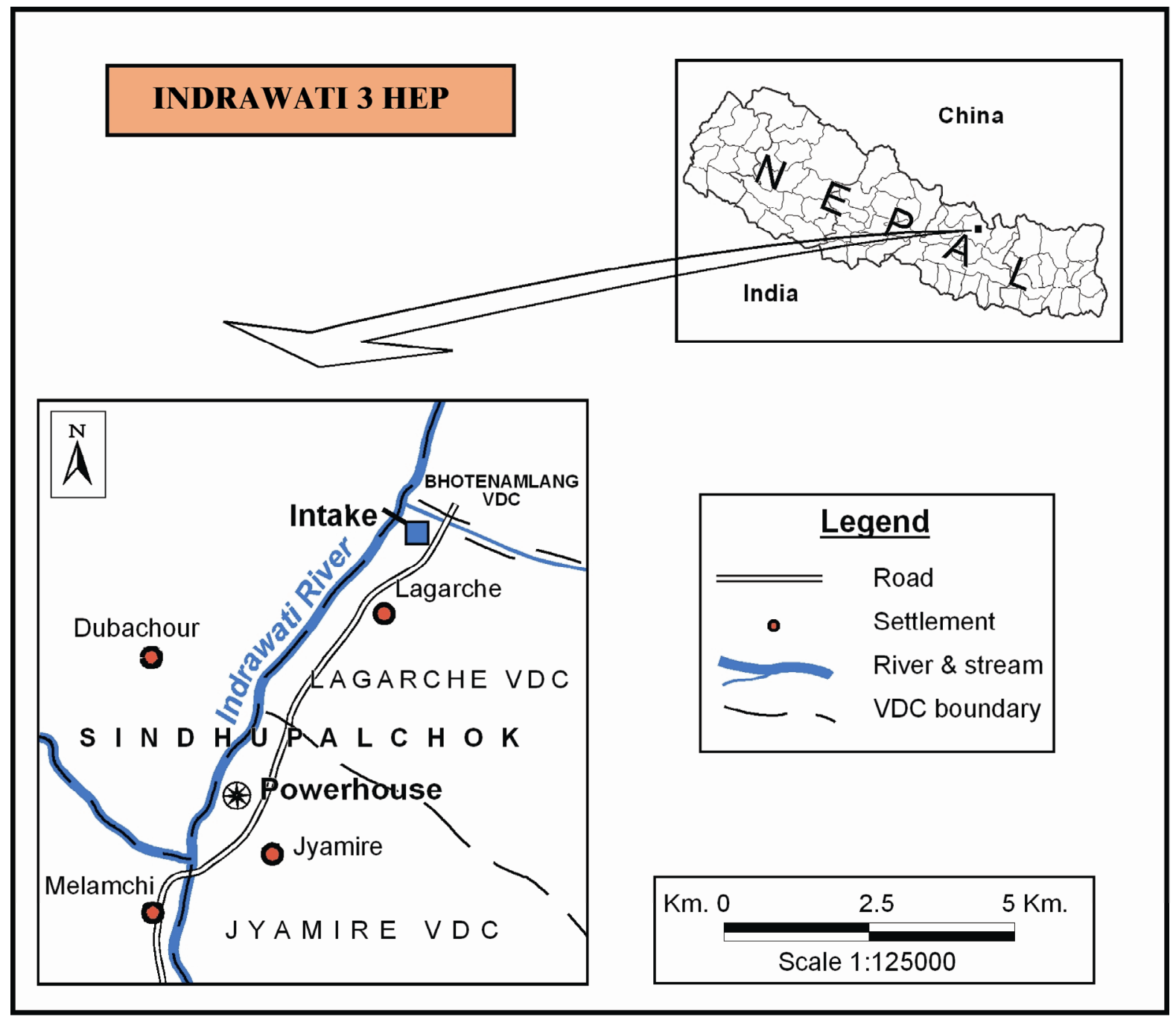

Figure 1. Location of indrawati 3 hydropower project, Nepal.

- The use of structured questionnaires,

- Interaction Matrices; Simple Matrices and Leopold Matrix,

- Use of GIS,

- Overlay techniques,

- Impact Networks,

- Task-specific Computer Models, and

- Ranking and weighting methods.

The second stage of the process predicting the impact in terms of magnitude, extent and duration of each impact identified. This was carried out through the intensive interactions among professional experts, stakeholders, and local people. A series of meetings were held for impact prediction and finally they were accepted by all.

Importance Weighing is the most structured approach to impact rating. It permits direct transformation of a sum of impact magnitude, extent, and duration into impact significance. Importance weightings of the resources likely to be affected were determined by organizing a workshop or a meeting to discuss at which representatives of the local people, local agencies, NGO stakeholders and the technical experts involved in EIA study have participated, A series of steps were followed by each participant/organizer as given by Rau and Wooten [8] while conducting meetings for the determination of weighting. Total scores of prediction were multiplied by importance weighting which resulted in developing a framework for determining the impact significance.

Thus, determination of significance provided the impact framework which contributed in the following:

- Categorization of impacts into most detrimental and most beneficial,

- Prioritization of impacts for which major resources 
and efforts can be allocated for minimizing the effects of highly detrimental impacts and enhancing the benefits from highly beneficial ones, and

- Dropping down the insignificant impacts of project implementation [6].

\section{Results and Discussion}

\subsection{Identification of Environmental Impacts}

Indrwati-3 Hydropower project constitute the construction of a water diversion weir, headrace tunnel, powerhouse, and other ancillary infrastructures. In the process of project construction and operation, the following adverse and beneficial impacts were likely to occur.

Physical Impacts (Adverse and Beneficial)
Micro-climate and air quality
Topography, land use, and stability
Surface erosion
Disposal of excavated materials
Hydrology and Sedimentation
Water Quality/Pollution
Solid Waste
Noise and Vibration
Impacts on Biological resources
Loss of forest cover
Increase in felling of trees
Exploitation of NTFP
Impact on Biodiversity
Impact on Rare Endangered and threatened
species
Impact on fish migration
Effect on Riparian Habitat
Downstream effect

Impacts on Socio-Economy and Cultural Resources Impacts in agricultural land

Women and Child Labor

Culture and Religion

Public Health

Occupational Health and Safety

Law and Order

Impact on local Life Style

Increase Pressure on Local Services

Increased local Employment

Increase in Local Trade

Improvement in Road Condition

Rural Electrification

Industrialization

Promotion in Eco-tourism

\subsection{Predicting Anticipated Impacts}

Based on the list above, the impacts were predicted. Each impact was predicted in terms of magnitude, extent, and duration. In predicting the impacts, ranking methods as given in National Environmental Impact Assessment Guidelines [11] and Canadian Federal Environmental Assessment Review [10] were followed. As specified earlier, a series of meetings were held with the participation of professional experts, stakeholders, affected people, and beneficiaries. In the preliminary meeting, a list of anticipated impacts was prepared and presented. The meeting was attended by all the experts involved in the EIA study. Each impact was discussed and predicted in terms of magnitude, extent, and duration. Based on the outcome of the preliminary meeting a Framework of Impact Prediction (FIP) was developed and presented in following meeting. A confirmation meeting was held immediately upon the finalization of FIP. The opinions and expressions of local people, local authorities, NGOs, and other stakeholders present in the meeting were recorded. The final meeting of experts made the necessary modifications to the predictions. The prediction made for the anticipated impacts of Indrawati-3 Hydropower Project are given in the Table 2:

\subsection{Ranking of the Predicted Impact}

Each of predicted impact is categorized into magnitude extent and duration. Further, on the basis of severity, impacts are classified as high $(\mathrm{H})$, moderate $(\mathrm{Mo})$ and low (Mi) under magnitude, in which $(\mathrm{H})$ is irreversible, and (Mo) and (Lo) are reversible. Under the extent, impact are classified as site specific (Sp), local (L) and regional (R). Similarly under duration, impacts were classified into short term (St), medium term (Mt) and long term (Lo). Each of the categories were the trans- lated into numerical value as given in National EIA guidelines (1993). The total numerical values were summed up to a maximum of 140 and minimum up to 35 (Table 3).

\subsection{Determining Importance Weighting}

Importance weighting is a structured approach to impact rating and permit a direct transformation of sum of impact magnitude, extent and duration into impact significance. Weighting can be determined by organizing a workshop or a meeting represented by local people, local agencies, NGOs stakeholders and the experts involved in EIA study.

The meeting held on 25 January, 2002 assigned importance value to the resources to be affected. An interacttion table was prepared where resources anticipated to be affected were listed in the vertical column and the importance weighting was marked in the horizontal column, indicating the degree of importance from 1 - 3 where 1 stands for the least importance and 3 indicates the highest importance. Table 4 provides the overall 
Table 2. Impact prediction in terms of magnitude, extent and duration.

\begin{tabular}{|c|c|c|c|c|c|c|c|c|c|}
\hline \multirow[t]{2}{*}{ Impacts } & \multicolumn{3}{|c|}{ Magnitude } & \multicolumn{3}{|c|}{ Extent } & \multicolumn{3}{|c|}{ Duration } \\
\hline & $\mathrm{H}$ & Mo & Mi & $\mathrm{R}$ & $\mathrm{L}$ & Sp & $\mathrm{Lt}$ & Mt & St \\
\hline \multicolumn{10}{|l|}{ Physical Environment } \\
\hline Micro-climate and air quality & - & - & $\mathrm{Mi}$ & - & - & Sp & - & - & St \\
\hline Topography, land use and stability & - & Mo & - & - & $\mathrm{L}$ & - & - & - & St \\
\hline Disposal of excavated materials & - & Mo & - & - & $\mathrm{L}$ & - & - & Mt & - \\
\hline Hydrology and Sedimentation & - & - & $\mathrm{Mi}$ & - & $\mathrm{L}$ & - & - & Mt & - \\
\hline Water Quality/Pollution & - & Mo & - & - & $\mathrm{L}$ & - & - & - & St \\
\hline Solid Waste & - & - & $\mathrm{Mi}$ & - & - & Sp & - & - & St \\
\hline Noise and Vibration & - & Mo & - & - & $\mathrm{L}$ & - & - & - & St \\
\hline \multicolumn{10}{|l|}{ Biological Environment } \\
\hline Loss of forest cover & - & Mo & - & - & $\mathrm{L}$ & - & - & Mt & - \\
\hline Impact on Biodiversity & - & Mo & - & - & $\mathrm{L}$ & - & - & - & St \\
\hline Impact on Rare Endangered and threatened species & - & Mo & - & - & $\mathrm{L}$ & - & - & Mt & - \\
\hline Impact on fish migration & - & - & $\mathrm{Mi}$ & - & $\mathrm{L}$ & - & - & Mt & - \\
\hline Effect on Riparian Habitat & - & - & $\mathrm{Mi}$ & - & $\mathrm{L}$ & - & - & Mt & - \\
\hline Downstream effects & - & Mo & - & - & $\mathrm{L}$ & - & - & Mt & - \\
\hline \multicolumn{10}{|l|}{ Socio-economic/Cultural Impact } \\
\hline Loss of agricultural land & $\mathrm{H}$ & - & - & - & $\mathrm{L}$ & - & - & Mt & - \\
\hline Women and Child Labor & - & Mo & - & - & - & Sp & - & - & St \\
\hline Culture and Religions & - & Mo & - & - & $\mathrm{L}$ & - & - & - & St \\
\hline Public Health & - & Mo & - & - & $\mathrm{L}$ & - & - & Mt & - \\
\hline Occupational Health and Safety & - & Mo & - & - & - & Sp & - & - & St \\
\hline Law and Order & - & - & $\mathrm{Mi}$ & - & - & Sp & - & - & St \\
\hline Impact on local Life Style & - & Mo & - & - & $\mathrm{L}$ & - & - & - & St \\
\hline Increase Pressure on Local Services & - & Mo & - & - & $\mathrm{L}$ & - & - & - & St \\
\hline Increased local Employment & - & Mo & - & $\mathrm{R}$ & - & - & - & Mt & - \\
\hline Increase in Local Trade & - & Mo & - & $\mathrm{R}$ & - & - & - & Mt & - \\
\hline Improvement in Road Condition & - & Mo & - & $\mathrm{R}$ & - & - & - & Mt & - \\
\hline Rural Electrification & - & Mo & - & $\mathrm{R}$ & - & - & $\mathrm{Lt}$ & - & - \\
\hline Promotion in Eco-tourism & - & Mo & - & $\mathrm{R}$ & - & - & $\mathrm{Lt}$ & - & - \\
\hline Decrease in Dependence on Fuel wood & - & Mo & - & - & - & - & $\mathrm{Lt}$ & - & - \\
\hline
\end{tabular}

$\mathrm{H}=$ High, $\mathrm{Mo}=$ Moderate, $\mathrm{Mi}=$ Minor, $\mathrm{R}=$ Regional, $\mathrm{L}=$ Local, $\mathrm{Sp}=$ Site Specific, $\mathrm{Lt}=$ Long Term, $\mathrm{Mt}=$ Medium Term, St $=$ Short Term $($ National Planning Commission, GON and IUCN-The World Conservation Union, 1993).

framework for assigning importance. The individual ranking of importance was then divided by the total score of importance value which provided the importance weighting of each resource to be affected by project implementation.

\subsection{Determination of Significance of Predicted Impacts in the Context of Indrawati-3 Hydropower Project}

The total score of numeral value of prediction of each impact (Table 3) was multiplied by importance weighting given in (Table 4). The product gives the relative impact of significance (Table 5). The higher the product, the more effects are associated with it. The impacts were then categorized and prioritized to invest greater efforts and resources for mitigating significant detrimental effects, while dropping down less significant effects.

\subsection{The Prioritization of Impacts for Designing Effective Mitigation Measures}

Table 5 provides a framework for impacts prioritization for designing an effective mitigation measures. Based on 
Table 3. The predicted impacts translated into numerical ranking as given by National Planning Commission, GON and IUCN-The World Conservation Union, 1993. [11]

\begin{tabular}{|c|c|c|c|c|c|c|c|c|c|c|}
\hline \multirow[t]{2}{*}{ Impacts } & \multicolumn{3}{|c|}{ Magnitude } & \multicolumn{3}{|c|}{ Extent } & \multicolumn{3}{|c|}{ Duration } & \multirow[t]{2}{*}{ Total } \\
\hline & $\mathrm{H}$ & Mo & $\mathrm{Mi}$ & $\mathrm{R}$ & $\mathrm{L}$ & Sp & $\mathrm{Lt}$ & Mt & St & \\
\hline \multicolumn{11}{|l|}{ Physical Environment } \\
\hline Micro-climate and air quality & - & - & 10 & - & - & 10 & - & - & 5 & 25 \\
\hline Topography, land use and stability & - & 20 & - & - & 20 & - & - & - & 5 & 45 \\
\hline Disposal of excavated materials & - & 20 & - & - & 20 & - & - & 10 & - & 50 \\
\hline Hydrology and Sedimentation & - & - & 10 & - & 20 & - & - & 10 & - & 40 \\
\hline Water Quality/Pollution & - & 20 & - & - & 20 & - & - & - & 5 & 45 \\
\hline Solid Waste & - & - & 10 & - & - & 10 & - & - & 5 & 25 \\
\hline Noise and Vibration & - & 20 & - & - & 20 & - & - & - & 5 & 45 \\
\hline \multicolumn{11}{|l|}{ Biological Environment } \\
\hline Loss of forest cover & - & 20 & - & - & 20 & - & - & 10 & - & 50 \\
\hline Impact on Biodiversity & - & - & 10 & - & - & 10 & - & 10 & - & 30 \\
\hline Impact on Rare Endangered and threatened species & - & 20 & - & - & 20 & - & - & 10 & - & 50 \\
\hline Impact on fish migration & - & - & 10 & - & 20 & - & - & 10 & - & 40 \\
\hline Effects on Riparian Habitat & - & - & 10 & - & 20 & - & - & 10 & - & 40 \\
\hline Downstream effects & - & 20 & - & - & 20 & - & - & 10 & - & 50 \\
\hline \multicolumn{11}{|l|}{ Socio-economic/Cultural Impact } \\
\hline Loss of Agriculture land & 60 & - & - & - & 20 & - & - & 10 & - & 90 \\
\hline Women and Child Labor & - & 20 & - & - & - & 10 & - & - & 5 & 35 \\
\hline Culture and Religions & - & 20 & - & - & 20 & - & - & - & 5 & 45 \\
\hline Public Health & - & 20 & - & - & 20 & - & - & 10 & - & 50 \\
\hline Occupational Health and Safety & - & 20 & - & - & - & 10 & - & - & 5 & 35 \\
\hline Law and Order & - & - & 10 & - & - & 10 & - & - & 5 & 25 \\
\hline Impact on local Life Style & - & 20 & - & - & 20 & - & - & - & 5 & 45 \\
\hline Increased on Pressure on Local Services & - & 20 & - & - & 20 & - & - & - & 5 & 45 \\
\hline Increased local Employment & - & 20 & - & 60 & - & - & - & 10 & - & 90 \\
\hline Increase in Local Trade & - & 20 & - & 60 & - & - & - & 10 & - & 90 \\
\hline Improvement in Road Condition & - & 20 & - & 60 & - & - & - & 10 & - & 90 \\
\hline Rural Electrification improvement & - & 20 & - & 60 & - & - & 20 & - & - & 100 \\
\hline Promotion in Eco-tourism & - & 20 & - & 60 & - & - & 20 & - & - & 100 \\
\hline Decrease in Dependence on Fuel wood & - & 20 & - & - & 20 & - & 20 & - & - & 60 \\
\hline
\end{tabular}

Source: National Hydropower Company Pvt, 2002; The values have been assigned as per the values given in National Environmental Impact Assessment Guidelines (NPC Government of Nepal and IUCN, 1993). 
Table 4. Importance weighting as decided by expert group (Extracted from EIA of Indrawati-3 Hydropower Project).

\begin{tabular}{|c|c|c|c|c|c|}
\hline \multirow{2}{*}{$\begin{array}{l}\text { Impacts } \\
\text { Physical Environment }\end{array}$} & \multicolumn{5}{|c|}{ Importance Value } \\
\hline & 1 & 2 & 3 & Total & Importance Weighting \\
\hline Micro-climate and air quality & $\sqrt{ }$ & & & 1 & 0.01960 \\
\hline Geology and topography & & $\sqrt{ }$ & & 2 & 0.03921 \\
\hline Hydrology and Sedimentation & & $\sqrt{ }$ & & 2 & 0.03921 \\
\hline Water Quality & $\sqrt{ }$ & & & 1 & 0.01960 \\
\hline Solid Waste & $\sqrt{ }$ & & & 1 & 0.01960 \\
\hline Tranquility of the area & & $\sqrt{ }$ & & 2 & 0.03921 \\
\hline \multicolumn{6}{|l|}{ Biological Environment } \\
\hline Forest cover & & $\sqrt{ }$ & & 2 & 0.03921 \\
\hline NTF & $\sqrt{ }$ & & & 1 & 0.01960 \\
\hline Cultivated land & $\sqrt{ }$ & & & 1 & 0.01960 \\
\hline Wild Life Habitat & & $\sqrt{ }$ & & 2 & 0.03921 \\
\hline Rare Endangered and threatened species & & & $\sqrt{ }$ & 3 & 0.05882 \\
\hline Fish species & & $\sqrt{ }$ & & 2 & 0.03921 \\
\hline Riparian Habitat & $\sqrt{ }$ & & & 1 & 0.01960 \\
\hline \multicolumn{6}{|l|}{ Socio-economic/Cultural Impact } \\
\hline Land property & & & $\sqrt{ }$ & 3 & 0.05882 \\
\hline Women and Child & & $\sqrt{ }$ & & 2 & 0.03921 \\
\hline Culture and Religions & & $\sqrt{ }$ & & 2 & 0.03921 \\
\hline Occupational Health and Safety & & $\sqrt{ }$ & & 2 & 0.02489 \\
\hline Law and Order & $\sqrt{ }$ & & & 1 & 0.01960 \\
\hline Local Services & & $\sqrt{ }$ & & 2 & 0.03921 \\
\hline Employment & & & $\sqrt{ }$ & 3 & 0.05882 \\
\hline Water Use & $\sqrt{ }$ & & & 1 & 0.01960 \\
\hline Local Trade & & $\sqrt{ }$ & & 2 & 0.03921 \\
\hline Road Condition & $\sqrt{ }$ & & & 1 & 0.01960 \\
\hline Rural Electrification & & & $\sqrt{ }$ & 3 & 0.05882 \\
\hline Industrialization & & & $\mathrm{V}$ & 3 & 0.05882 \\
\hline Eco-tourism & & $\sqrt{ }$ & & 2 & 0.03921 \\
\hline Total & & & & 51 & 1.000 \\
\hline
\end{tabular}

Note: 1 = least importance, 2 = moderate importance and $3=$ most important. 
Table 5. Impact significance and prioritization for mitigation prescription.

\begin{tabular}{|c|c|c|c|c|c|}
\hline Predicted Impacts & $\begin{array}{l}\text { Total Score } \\
\text { from Ranking } \\
\text { (Table 3) }\end{array}$ & & $\begin{array}{c}\text { Importance } \\
\text { Weighting } \\
\text { (Table 4) }\end{array}$ & $\begin{array}{l}\text { Significant } \\
\text { Values }\end{array}$ & $\begin{array}{c}\text { Impact Prioritization } \\
\text { (1 = top priority) }\end{array}$ \\
\hline \multicolumn{6}{|l|}{ Physical Environment } \\
\hline Topography, land use and stability & 45 & $\mathrm{U}$ & 0.03921 & 1.764 & 9 \\
\hline Disposal of excavated materials & 50 & $\begin{array}{l}\mathrm{L} \\
\mathrm{T}\end{array}$ & 0.03921 & 1.960 & 8 \\
\hline Hydrology and Sedimentation & 40 & $\begin{array}{l}\mathrm{T} \\
\mathrm{F}\end{array}$ & 0.01960 & 0.784 & 15 \\
\hline Water Quality/Pollution & 45 & $\begin{array}{l}\mathrm{r} \\
\mathrm{I}\end{array}$ & 0.01960 & 0.882 & 14 \\
\hline Solid Waste & 25 & $\mathrm{C}$ & 0.03921 & 0.980 & 13 \\
\hline Noise and Vibration & 45 & A & 0.03921 & 1.764 & 9 \\
\hline \multicolumn{6}{|l|}{ Biological Environment } \\
\hline Loss of forest cover & 50 & I & 0.01960 & 0.980 & 13 \\
\hline Impact in Biodiversity & 30 & $\begin{array}{l}\mathrm{O} \\
\mathrm{N}\end{array}$ & 0.01960 & 0.588 & 17 \\
\hline Impact on Rare Endangered and threatened species & 50 & $\begin{array}{l}\mathrm{O} \\
\mathrm{N}\end{array}$ & 0.03921 & 1.960 & 8 \\
\hline Impact on fish migration & 40 & $\mathrm{~F}$ & 0.05882 & 2.352 & 7 \\
\hline Effect on Riparian Habitat & 40 & & 0.03921 & 1.568 & 10 \\
\hline \multicolumn{6}{|l|}{ Socio-economic/Cultural Impact } \\
\hline Loss of Agriculture land & 90 & & 0.05882 & 5.293 & 2 \\
\hline Women and Child Labor & 35 & $\begin{array}{c}\mathrm{I} \\
\mathrm{M}\end{array}$ & 0.03921 & 1.372 & 11 \\
\hline Culture and Religions & 45 & $\begin{array}{l}\mathrm{M} \\
\mathrm{P}\end{array}$ & 0.03921 & 1.764 & 9 \\
\hline Occupational Health Hazardous and Safety & 35 & $\mathrm{O}$ & 0.01960 & 0.686 & 16 \\
\hline Law and Order & 25 & $\mathrm{R}$ & 0.03921 & 0.980 & 13 \\
\hline Impact on local Life Style & 45 & $\mathrm{~T}$ & 0.05882 & 2.646 & 6 \\
\hline Increase Pressure on Local Services & 45 & A & 0.01960 & 0.882 & 14 \\
\hline Increased in local Employment & 90 & $\mathrm{~N}$ & 0.03921 & 3.528 & 4 \\
\hline Increase in Local Trade & 90 & $\begin{array}{l}\mathrm{C} \\
\mathrm{E}\end{array}$ & 0.01960 & 1.521 & 10 \\
\hline Improvement in Road Condition & 90 & $\mathrm{E}$ & 0.05882 & 5.293 & 2 \\
\hline Rural Electrification & 100 & W & 0.05882 & 5.882 & 1 \\
\hline Promotion in Eco-tourism & 100 & $\mathrm{E}$ & 0.03921 & 3.921 & 3 \\
\hline Decrease in Dependence on Fuel wood & 60 & $\begin{array}{l}\mathrm{T} \\
\mathrm{I} \\
\mathrm{N} \\
\mathrm{G}\end{array}$ & 0.01960 & 1.176 & 12 \\
\hline
\end{tabular}

Source: National Hydropower Company Pvt, 2002.

priority and severity the predicted impacts were classified into following three categories:

\author{
Impacts having significant adverse/beneficial effects \\ Rural Electrification—beneficial \\ Local employment—beneficial \\ Promotion in Ecotourism—-beneficial \\ Loss of Agricultural land-adverse \\ Disposal of excavated materials-adverse \\ Decrease in dependence on fuel wood-beneficial \\ Promotion of ecotourism-beneficial \\ Loss of forest cover/forest biomass-adverse \\ Impact on rare/endangered/endemic species of plants \\ and animals downstream effects—adverse \\ Topography, land use and stability—adverse \\ Noise and vibration-adverse \\ Habitat encroachment—adverse \\ Effects on culture and religious-adverse \\ Hydrology and sedimentation-adverse \\ Impact on fish migration-adverse
}

Impacts with Moderate/Adverse/Beneficial Effects
Occupational health hazards_-adverse

Women and child labor-adverse

Exploitation of NTFP-adverse

Impacts on life style-adverse

Water quality / pollution-adverse

Effects on riparian habitat-adverse

Impacts with Less Significant Adverse/Beneficial Ef-

fects

Improvement in road condition-beneficial

Law and order-adverse

Micro-climate and air quality-adverse

Solid waste-adverse

\section{Conclusions}

The entire process as outlined above for the identification of significant impacts is a subjective exercises involving mostly judgment values of experts, stakeholders, project affected and beneficiaries and other concerned people of the local area. But for those parameters of environment, whose national and international standards or 
norms are available, the values anticipated from the study can be compared and the thesholds can be determined. For example, air and water quality and noise level can be compared against national quality standards. For impacts, whose severity is not quantifiable such as social issues, this process of quantification, would be most appropriate, since it involves the project affected stakeholders of project areas. The authors believe that the impact predicted and quantified through this method would likely to be more closer to the reality of the local area, since it involves the local people likely to be affected by the project implementation [14].

Determination of significance provides the impact framework on categorization of impacts into most detrimental and most beneficial ones and prioritizes the impacts for which major resources and efforts can be allocated for reducing highly detrimental effects and enhancing benefits from highly beneficial impacts [6]. All scores are relative and computation methods are based on subjective judgment value. Therefore, it does not have any scientific foundation [8]. However, in the process of EIA of a development project, many impacts are usually identified; some of them are significantly detrimental or beneficial but most of them are insignificant in terms of their severity, albeit, they are equally treated and wrongly predicted. In such circumstances, the project proponent faces dilemma as to where to place more resources and efforts in order to minimize the detrimental effects or to enhance beneficial effects of project implementation. Therefore, categorization of impacts in terms of severity is more desirable [14] for:

- Designing the most effective mitigation measures investing adequate amount of time, money and efforts, to minimize the most significant adverse impacts,

- Paying less attention and efforts on moderate and less significant impacts,

- Providing a coherent linkage among the various issues addressed in EIA report,

- Providing specific monitoring and auditing linkage to the specific impacts and mitigation measures proposed, and above all, concentrating more on highly significant impacts, thus, avoiding the insignificant ones.

Furthermore, the quantification of impacts and their categorization is important because the decision makers usually require a strong basis to make a decision on the proposed project implementation. It would be rather difficult for project proponent to convince the decision maker through descriptive narration; but quantification of the description is likely to ease the decision makers to grasp the essence of the issues to be decided particularly in developing country.

\section{Acknowledgements}

The authors are highly grateful to the Authorities of Indrawati-3 Hydropower Project Nepal for the permission to use their information. The help provided by the people responsible for collecting information, the local stakeholders who provided their valuable suggestions, and the experts who examined the validity of the issues are highly appreciated.

\section{REFERENCES}

[1] R. Sippe, "Criteria and Standard for Assessing Significant Impact,” In: J. Petts, Ed., Handbook of Environmental Assessment, Blackwell Science LtD., Oxford, Vol. 1, 1999.

[2] M. A. Thompson, "Determining Impact Significance in EIA: A Review of 24 Methodologies," Journal of Environmental Management, Vol. 30, 1990, pp. 235-250. doi:10.1016/0301-4797(90)90004-G

[3] G. E. Beanlands and P. N. Duinker, “An Ecological Framework for Environmental Impact Assessment in Canada," Dalhousie University and FEARO Canada, Halifax, 1983.

[4] P. T. Hauge, et al., "Determining the Significance of Environmental Issue under the National Environmental Policy Act,” Journal of Environmental Management, Vol. 18, 1984, pp. 15-24

[5] A. Gilpin, "Environmental Impact Assessment: Cutting Age for the $21^{\text {st }}$ Century," Cambridge University Press, London, 1995.

[6] M. H. Sadar, "Environmental Impact Assessment," Carleton University Press for Impact Assessment Center, Carleton, 1996.

[7] Australian and New Zealand Environment and Conservation Council, "A National Approach to Environmental Impact Assessment in Australia, Anzecc Secretariat," 1991.

[8] G. J. Rau and D. C. Wooten, "Environmental Impact Assessment Handbook,” McGraw-Hill Book Company, New York, 1980.

[9] L. W. Canter, "Environmental Impact Assessment," McGraw-Hill Book Company, New York, 1996.

[10] Canadian Federal Environmental Assessment Review Office (REARO), "Environmental Screening and Initial Assessment Guidelines,” FEARO, 1986.

[11] National Planning Commission, Government of Nepal and IUCN, "National Environmental Impact Assessment Guidelines,” NCSIP, Kathmandu, 1993.

[12] Shah Consult International (P) LtD, "Feasibility Study and Initial Environmental Examination of Indrawati-3 Hydropower project for the Government of Nepal,” 1997.

[13] Government of Nepal, "Environmental Protection Regulation,” Government Press Nepal, 1997.

[14] R. B. Khadka and H. Shrestha, "The Scoping Process for Environmental Impact Assessment of Project: A Case 

Environmental Impact Assessment of Indrawati-3 Hydropower Project in Nepal

Study of Outer-Ring Road Project in Nepal-Based on Local: People's Perception,” The International Journal of Environmental, Cultural Economic and Social Sustainability, Vol. 4, No. 3, 2008, pp. 25-36.

[15] National Hydropower Company, Pvt, "Environmental
Impact Assessment (EIA) of Indrawati-3 Hydropower Project-Approved by the Government of Nepal,” 2002.

[16] R. B. Khadka and S. Gorzula, "Environmental Impact Assessment (EIA),” Pokhara University, Pokhara, 2010, pp. 1-136. 